\title{
Delirium - a common condition associated with negative outcome in the elderly
}

\author{
Vibeke Juliebø $^{1,2}$, Maria Krogseth ${ }^{2,3}$, Bjørn Erik Neerland ${ }^{2,3}$, Leiv Otto Watne ${ }^{2,3}$ and \\ Torgeir Bruun Wyller ${ }^{2,3}$ \\ 1) Department of Cardiology, Ullevål, Oslo University Hospital, Norway \\ 2) Department of Geriatric Medicine, Oslo University Hospital, Norway \\ 3) Faculty of Medicine, University of Oslo, Norway \\ Correspondence: Vibeke Juliebø, Department of Cardiology, Ullevål, Oslo University Hospital, P.O. Box 4956 Nydalen, N-0424 Oslo, Norway \\ E-mail: v.juliebo@gmail.com Telephone+4741268759
}

\begin{abstract}
Delirium ("acute confusional state"), characterized by an acute decline in attention and cognition, is a common clinical syndrome in elderly patients. The prevalence of delirium increases with age, and is highest among hospitalized older patients. A systematic literature search of MEDLINE, EMBASE, and the Cochrane Library limited to the period 2000-2012 was conducted.

The antecedent of delirium is often multifactorial, the development involving a complex interrelationship between a vulnerable patient with predisposing factors and exposure to precipitating events. Important predisposing factors include high age, cognitive impairment, comorbidity, sensory impairment, and low Body Mass Index (BMI). Infections, cardiovascular events, trauma/fracture, surgery, stroke, metabolic abnormalities, and dehydration, are all recognized as precipitating factors.

Delirium is associated with negative outcomes like cognitive decline, increased morbidity and mortality, and should be prevented. Prevention and treatment of delirium is multifactorial and multidisiplinary, focusing on the treatment of factors precipitating and maintaining the delirium. No pharmacological treatment has so far demonstrated significant efficacy. The knowledge of risk factors and the underlying pathophysiological mechanisms involved remains scarce, and further research is warranted to explore the mechanisms and thereby develop targeted prevention and treatment strategies.
\end{abstract}

\section{INTRODUCTION}

Delirium, formerly often called "acute confusional state", is characterized by an acute decline in attention and cognition. It is a common clinical syndrome in elderly patients and among the most frequent in-hospital acquired complications. The prevalence of delirium is especially high among hip fracture patients, in patients undergoing cardiac surgery, in patients with acute medical illness or stroke, and in intensive care units (ICU). Delirium among home-dwellers and patients in long term care is less explored.

According to DSM IV-TR, the diagnostic criteria for delirium comprise impaired consciousness, impaired cognition, a rapid onset with symptoms tending to fluctuate, and an identifiable underlying organic pathology (1) (textbox 1). The level of psychomotor activity can be either increased (agitated/hyperactive delirium) or decreased (hypoactive delirium), and the diagnostic criteria for delirium continue to develop as research in the field progresses $(2,3)$. The diagnosis of delirium is primarily clinical, and understanding its clinical symptoms is essential. The diagnosis is based on bedside observation, and diagnostic algorithms like the Confusion Assessment Method (CAM) (4) are widely used (textbox 2).

The aim of this review is to make a brief summary of the main aspects of delirium; the epidemiology, outcomes and pathophysiology. A systematic literature search of MEDLINE, EMBASE, and the Cochrane Library limited to the period 2000-2012 was conducted with the search words 1) delirium, 2) delirium AND elderly, 3) delirium AND risk factors, 4) delirium AND prevention, 5) delirium AND treatment, 6) delirium AND pathophysiology, 7) delirium AND coronary surgery, 8) delirium AND stroke, 9) delirium AND medical patients, 10) delirium AND hip fracture, 11) delirium AND nursing homes, 12) delirium AND dementia, and 13) delirium AND mortality. Reviews and original reports of observational and intervention studies were considered for inclusion.

Textbox 1. Diagnostic criteria for delirium, DSM IV-TR (1).

A. Disturbance of consciousness (i.e., reduced clarity of awareness of the environment) with reduced ability to focus, sustain, or shift attention.

B. A change in cognition (such as memory deficit, disorientation, language disturbance) or the development of a perceptual disturbance that is not better accounted for by a preexisting, established, or evolving dementia.

C. The disturbance develops over a short period of time (usually hours to days) and tends to fluctuate during the course of the day.

D. There is evidence from the history, physical examination, or laboratory findings that the disturbance is caused by the direct physiological consequences of a general medical condition. 
Textbox 2. Confusion Assessment Method (CAM) (4). The diagnosis of delirium by CAM requires the presence of features $\mathrm{a}$ and/or $\mathrm{b}$ and either $\mathrm{c}$ or $\mathrm{d}$.

(a) Acute onset and fluctuating course: evidence of an acute change in mental status from the patient's baseline that changes in severity during the day.

(b) Inattention: patient has difficulty focusing attention for example, is easily distractible or has difficulty keeping track of conversation.

(c) Disorganized thinking: patient's thinking is disorganized or incoherent, as evidenced by rambling or irrelevant conversation and unclear or illogical flow of ideas.

(d) Altered consciousness: a rating of a patient's level of consciousness as other than alert (normal) - that is, vigilant or hyperalert, lethargic or drowsy, stuporous or comatose.

\section{THE EPIDEMIOLOGY OF DELIRIUM}

The prevalence of delirium increases with age, and is highest among hospitalized older patients. Among elderly in-hospital patients, the occurrence rate of delirium per admission varies from 11 to $42 \%$ in different studies (5). The occurrence of delirium is even higher among surgical patients, and up to half of all elderly surgical patients develops delirium postoperatively (6). The antecedent of delirium is often multifactorial, the development involving a complex interrelationship between a vulnerable patient with predisposing factors and exposure to precipitating events $(6,7)$. Predisposing factors include cognitive impairment, comorbidity, low Body Mass Index (BMI) and sensory impairments.

Precipitating events are the factors triggering the pathophysiological mechanisms resulting in delirium. Some of these factors are modifiable and therefore potential targets for prevention. In patients with many or severe predisposing factors, delirium may develop after exposure to a relatively benign insult like a urinary tract infection or anxiolytic therapy. Delirium might be the only symptom of serious disease like myocardial infarction or chest infection in vulnerable, elderly patients. On the contrary, in patients without predisposing factors, delirium may develop only after one or several harmful insults like trauma or sepsis (6). In medical, surgical, and ICU settings, different types of infections (pneumonia, sepsis, urinary tract infection) are shown to be independent risk factors for delirium (8).

Although the knowledge of delirium is increasing, the syndrome is often overlooked in clinical practice. Especially in patients with hypoactive delirium the syndrome is often ignored, explaining why clinicians might have the impression that the reported prevalence of delirium in research is overestimated.

Persistent delirium is a term that has come into use the last years, describing a condition where the delirium symptoms have failed to resolve and the patients have developed a more chronic cognitive impairment. Delirium was previously considered as an acute, rever- sible confusional state, but recent studies have reported that delirium may last for months and years.

Several multifactorial and multidisciplinary studies have indicated that delirium is preventable, and treatment of delirium is focusing on management of the precipitating factors, as well as avoiding hypoxia, hyperthermia and electrolyte disturbances $(9,10)$. Interventions including staff-education, early mobilization, reorientation to compensate for cognitive impairment, maintenance of circadian rhythm, and the use of aids to compensate for sensory impairment, have been shown to reduce the development of delirium. In the few randomized controlled trials carried out on delirium prevention, the reduction rate of delirium range from $10.1 \%$ to $20.4 \%$ (11-13). Antipsychotics and anxiolytics are widely used in the treatment of delirium, but except for a couple of studies indicating a prophylactic effect of haloperidol and risperidon on the incidence, duration and severity of delirium, no study has so far demonstrated substantial benefit on the outcome after delirium (14-16). A recently published study indicates that ondansetron may be an effective agent with fewer side effects in treating delirium (17).

\section{DELIRIUM IN HIP FRACTURE PATIENTS}

An expanding number of studies on delirium in hip fracture patients have been published in the recent decades, reporting incidence rates varying from $4 \%$ to $54 \%(18-27)$. The published studies are heterogeneous with respect to reported risk factors (28). Small studies tend to report higher incidence rates than larger studies (29). The heterogeneity in assessment methods, monitoring frequency, inclusion criteria, small sample sizes, publication bias (small studies with low incidence rates are not being published), and the limited number of potential risk factors studied might explain the variations in incidence rates and risk factors (28-30).

Hip fracture is considered to be a harmful insult, and delirium may develop as result of a hip fracture also in patients without predisposing factors (7). Premorbid cognitive impairment is the most common risk factor for delirium identified across several studies. Other risk factors, including age, male sex, medications, comorbidity, and perioperative risk factors, are inconsistently reported (28-30), and the risk factors may differ in patients with and without prefracture cognitive impairment. A recently published study indicate that malnutrition and delay to surgery are important risk factors for delirium in hip fracture patients (23).

Several studies on delirium have excluded patients with prefracture dementia or severe dementia. Because patients with dementia have been shown to be most prone to develop delirium, it is likely that a large proportion of patients with delirium have been excluded from these studies (31). Patients with dementia are often frail, and knowledge of risk factors is necessary to develop appropriate strategies to prevent delirium and any associated further decline of their cognitive and physical health. 
Moreover, only a few studies have made a distinction between preoperative and postoperative delirium $(20,23)$. In a hip fracture study, we found that $21 \%$ of the patients developed delirium preoperatively, while $35 \%$ of the patients who were lucid at admission developed delirium after the operation. Pre-fracture cognitive impairment or dementia and acquiring the fracture indoors were identified as independent risk factors for both preoperative and postoperative delirium. Hip fracture patients with moderate to severe cognitive impairment are more prone to develop delirium already before surgery compared to patients with no or mild cognitive impairment (23). The risk factor profile seems to differ between preoperative and postoperative delirium, as also found by others (20). Time from admission to operation has been identified as an independent risk factor for preoperative delirium, increasing the risk of delirium by $5 \%$ per hour, whereas BMI below 20 seems to be an important predictor of postoperative delirium (23). Delay of surgery may be caused by administrative problems, delay of evaluation of medical comorbidities, and time required for stabilization of medical conditions (32). Previous studies have emphasized the fact that medical comorbidities rarely require delayed operation (33), on the contrary, frail elderly patients suffering from dementia and multiple comorbidities should be prioritized for operation to avoid complications. These findings supports the hypothesis of surgical delay as a cause of complications rather than a result of medical conditions, but one cannot rule out the possibility that the surgical delay is caused by a delay in medical evaluation and stabilization.

\section{DELIRIUM AFTER CARDIAC SURGERY}

Delirium is also a common complication after cardiac surgery, incidence reports ranging from $14 \%$ to $42 \%$ (34). The most established risk factors for delirium after cardiac surgery, identified across several studies, are atrial fibrillation, preoperative cognitive impairment, higher age, higher burden of comorbidity, depression, a history of stroke, and peripheral vascular disease $(35,36)$. Other important risk factors are a low cardiac output and the use of Intra Aortic Balloon Pump or inotropic medication.

Delirium after cardiac procedures has been shown to be associated with increased mortality (14\% in patients with delirium vs. $2 \%$ in those without), more hospital readmissions ( $46 \%$ vs. $27 \%$ ), and reduced quality of life (37). It is also associated with reduced cognitive functioning, including failures in attention, memory, perception, and motor function, and with functional dysfunction such as dependency in activities of daily living and mobility.

In a retrospective study including 8,474 patients undergoing coronary artery bypass grafting (CABG), 496 (6\%) developed postoperative delirium (36). Patients developing delirium appeared to have an increased long-term risk of death and stroke. Weaknesses of this study are the retrospective design and the fact that the authors did not systematically screen for delirium, explaining the low prevalence.

The increasing number of elderly patients going through cardiac procedures and the high rates of delirium in these groups emphasizes the demand of targeted prevention and management strategies of delirium in this population (36).

\section{DELIRIUM IN HOSPITALIZED MEDICAL PATIENTS}

In a systematic literature review, the prevalence of delirium in medical in-patients ranged between 10 and $31 \%$ at admission, and the incidence of new delirium per admission ranged from 3 to $29 \%$ (5). The prevalence of delirium in patients with dementia is even higher, up to $50 \%$ in medical wards (38). For intensive care units, the incidence of delirium among elderly patients is as high as between 70 and $87 \%$ (39).

Age and cognitive decline are the most important predisposing factors for delirium in medical in-patients (8). Previous episodes of delirium, neurological disease, stroke, falls and gait disorders are other nonmodifiable risk factors. In general, the risk of developing delirium increases progressively with the number of risk factors present (7). Sensory (vision and hearing) impairment is a risk factor for incident delirium as well as for its persistence. The evidence is strongest for visual impairment (40). In general, the evidence for precipitating factors is based on one or very few studies of different quality (8). Medication may contribute to the development of delirium, and may even be the solo precipitant in some cases. One systematic review has indicated medications to avoid in people at risk of delirium. Medications with deleterious effects on dopaminergic and cholinergic pathways, as well as benzodiazepines and opioids were studied. Opioids, benzodiazepines, dihydropyridines and antihistamines appear to be associated with increased risk of delirium (41). It is also plausible that polypharmacy per se increases the risk of developing delirium, but the evidence is scarce.

Stroke is a recognized predisposing factor for delirium, but until recently few prospective studies have been exploring delirium in the acute stroke setting $(42,43)$. The prevalence of delirium in acute stroke patients is reported to be in the range of $10 \%$ to $28 \%$, and independent risk factors include cognitive impairment, higher age, metabolic disturbances, intracerebral hemorrhage, and larger ischemic hemispheric strokes (42-44).

Few studies on delirium in medical patients use validated scales for severity of illness (like Acute Physiology and Chronic Health Evaluation (APACHE) II score). One study conducted in a medical ward found that $44 \%$ of the patients in the delirium group and $10 \%$ of the patients in the no-delirium group had severe illness, defined as an APACHE II score above 16. A study in ICU-patients has identified an approximately 
linear association between delirium and the severity of illness (OR 1.25 [95\% CI 1.23 to 1.27 ] per 5 point increase in APACHE II score) (45). A widely accepted laboratory measure of dehydration is the disproportionate rise in blood urea nitrogen (BUN) relative to creatinine. However, the cut-off ratio (e.g. BUN/creatinine $\geq 18$, as in one study (46)) is difficult to interpret, depends on the units used, and a high urea level is not specific for dehydration. There are only a few studies addressing this issue, and the results are not consistent. There is also low quality evidence suggesting that electrolyte disturbance is an independent risk factor for delirium (8), while immobilization, physical restraints and bladder catheters are shown to increase the risk for delirium (47). Moreover, low albumin, a sign of poor nutritional status, has been proposed as a risk factor for delirium (48), and one study has identified anemia as an independent risk factor for delirium in male patients (49).

\section{DELIRIUM IN LONG-TERM CARE}

The prevalence of delirium in nursing homes and residential homes are poorly documented, and the number of studies on delirium in these settings is low. The studies are heterogeneous with respect to the subjects' cognition, as well as to the instruments used to identify delirium. The reported prevalence range from $<0.5 \%$ to $58 \%(50-53)$.

The patients living in long term care facilities are often frail and possess a high number of predisposing factors. Therefore, few precipitating factors are needed to increase the probability of these residents to become delirious. A newly published study on delirium in long-term care, found that most episodes of delirium were preceded by a state of subsyndromal delirium, defined by one or more symptoms of delirium, but not meeting the full diagnostic criteria. Episodes of delirium were also followed by a state of subsyndromal delirium $(54,55)$. The observation supports the view that among frail nursing home residents, there might be a long period with prodromal symptoms of delirium and periods of exacerbations (54), explaining some of the diversity in the reported prevalences.

\section{DELIRIUM AND DEMENTIA}

Whereas delirium is an acute state, dementia is a chronic disorder with progressive decline in cognitive functions. According to the DSM IV-TR criteria, dementia is defined as the development of multiple cognitive deficits manifested by both memory impairment, and one or more of the following cognitive impairments: apraxia, aphasia, agnosia, disturbances in executive functioning. The cognitive deficits should cause significant impairment in social or occupational functioning, and the deficits should not occur exclusively during the course of a delirium (1).

Elderly people and people suffering from dementia are more prone to develop delirium (31). Brain imaging studies have indicated that vascular dysfunction may precede cognitive decline and neurodegenerative changes in Alzheimer's disease (AD) and AD models (56). Both delirium and dementia are associated with increased level of CRP and IL-6, and there is growing evidence that a low-grade inflammation is present in dementia, especially in Alzheimer's disease, but also in vascular dementia (57-60). Amyloid $\beta$-peptide, considered central in the pathogenesis of Alzheimer's disease, has also pronounced neuroinflammatory properties (61).

Moreover, there is increasing evidence that patients suffering from delirium have increased risk of developing dementia $(62,63)$. Until about a hundred years ago, delirium and dementia were considered as manifestations of the same disorder (64). Nowadays, most researchers and clinicians consider dementia and delirium to be separate clinical entities, though there are obvious links between them with respect to epidemiology and clinical presentation. Despite these links, patients with chronic cognitive impairment are often excluded from studies of delirium (31), and most of the studies of delirium and mortality lack information on the severity of cognitive impairment prior to the delirious episode $(65,66)$.

In order to better understand the association between delirium and dementia, the effect of delirium in patients without dementia were explored in a study also taking pre-morbid cognitive function into account. The study identified delirium as the most important risk factor for developing dementia after hip fracture (67). The effect of delirium upon incident dementia was stronger when adjusting for degree of pre-fracture cognitive decline (as assessed by the Informant Questionnaire on Cognitive Decline in the Elderly (IQCODE)) in the multivariate analysis, indicating that the risk of developing dementia after delirium is higher in patients with mild pre-fracture cognitive impairment (not fulfilling the diagnostic criteria for dementia). The results support the view that delirium may contribute to a chronic cognitive decline. It still remains to be explored whether delirium is a result of an acute brain damage which is also responsible for triggering active processes causing chronic cognitive impairment, or if delirium itself is neurotoxic (63).

\section{DELIRIUM AND MORTALITY}

Delirium has been associated with greater morbidity, longer length of hospital stay, and greater risk of institutionalization $(9,19,68)$. The association between delirium and mortality are inconsistently reported, and the reports are divergent regarding which subgroups are most sensible to the possible decreased survival (66, $69,70)$. One study reported delirium to be associated with increased mortality in surgical patients suffering from dementia (65), while a study of medical patients identified patients with delirium but without dementia to be at increased risk of death (71). Patients suffering from dementia are frailer and hence more prone to de- 
velop delirium. Medical patients without dementia developing delirium are more likely to be suffering from severe illness and therefore at higher risk of death.

A recent study demonstrated that delirium after cardiac procedures is associated with increased mortality, hospital readmission, and reduced quality of life (34). Persistent delirium has also been reported to be associated with increased mortality in patients with as well as without dementia (72). The divergent reports illustrate the fact that when assessing the association between delirium and mortality, one has to take into account the predisposing (cognitive impairment, comorbidity) as well as the precipitating factors. The relationship between delirium and chronic cognitive impairment remains to be explored.

Previous reports on the effect of delirium on mortality often lack important information on severity of cognitive impairment prior to the delirious episode. To better understand the effect of delirium upon mortality, the association between delirium and the severity of cognitive impairment prior to the delirious episode has been explored in a Norwegian study (73). We found that the severity of cognitive impairment, assessed by IQCODE, was an important predictor of mortality in elderly hip fracture patients. Delirium did not affect mortality in patients with normal cognition, whereas in those suffering from pre-fracture dementia there was a statistically non-significant increase in risk of death after delirium. Delirium superimposed upon dementia was associated with increased risk of death from dementia and stroke.

\section{PATHOPHYSIOLOGICAL MECHANISMS OF DELIRIUM}

Despite increasing focus on the clinical aspects of delirium during the last decade, the pathophysiological mechanism remains inadequately understood. Whereas the pathophysiological mechanisms in Alzheimer's disease are increasingly being elucidated, this knowledge has only to a very limited degree been transferred to the field of delirium. As previously mentioned, the factors precipitating delirium are heterogeneous, and many physiological and molecular mechanisms have been proposed. The leading hypotheses for the pathogenesis focus on neurotransmission, inflammation and chronic stress $(6,63,74,75)$. Even though there exists a considerably diversity in the precipitating factors of delirium, the clinical features are relatively homogeneous indicating one or several final common pathways.

A recently published report proposes to classify the etiologies of delirium into two major categories; 1) the direct brain insults and 2) the aberrant stress responses (75). Direct brain insults includes acute processes that affect brain function like energy deprivation, metabolic disturbances, trauma, hemorrhage or direct effects on the neurotransmitters by drugs. Drug induced delirium may be considered as a pharmacological direct brain insult, and drugs inducing delirium have given an indication regarding which neurotransmitters that might contribute (75). Anticholinergic drugs impairing central cholinergic transmission as well as drugs increasing dopaminergic tone have been reported to precipitate delirium (75-77).

The hypothesis of aberrant stress response focuses on inadequate responses to stressors like infections, surgical trauma and anxiety (75). There are, among others, two major aberrant stress responses; exaggerated inflammation-induced sickness behavior and Limbic-Hypothalamo-Pituitary-Adrenocortical (LHPA) axis dysfunction. In exaggerated inflammation-induced sickness behavior, systemic inflammatory signals are transmitted into the CNS and stimulate the synthesis of pro-inflammatory mediators, activating microglia cells and damaging neurons $(75,78)$.

The blood-brain barrier changes with increasing age and dementia, and a compromised blood-brain barrier will increase the central sensibility to systemic inflammation mediators. Extra-cerebral inflammation itself might also cause a blood-brain barrier disruption. Moreover, Alzheimer's disease and cerebrovascular pathology may affect the cholinergic, dopaminergic and noradrenergic systems, making them more prone to the influence of stress and inflammation (79-81).

Assuming an intact blood-brain-barrier, inflammatory signals in the periphery might be transmitted to the central nervous system (CNS) through a) direct communication in the circumventricular organs, b) activating endothelial cells in the cerebral vessels to secrete soluble prostaglandins into the brain parenchyma, and c) activating efferents of the vagus nerve (75).

Cortisol is the central hormone in the human stress response, and its level increases with stressors like acute illness, trauma, surgery, systemic inflammation, and pain. There is some evidence that persistent high levels of cortisol are associated with delirium, and treatment with corticosteroids may induce delirium in vulnerable patients $(75,82)$.

The role of inflammation and LPHA dysfunction needs to be further explored in future studies.

\section{CONCLUSION}

Delirium, characterized by an acute decline in attention and cognition, is a common and life-changing event. The prevalence of delirium increases with age, and is highest among hospitalized older people. Elderly patients suffering from acute illness, fractures or undergoing cardiac surgery are at high risk of developing delirium during the acute phase, and of subsequently developing dementia. The antecedent of delirium is often multifactorial, the development involving a complex interrelationship between a vulnerable patient with predisposing factors and exposure to precipitating factors $(6,7)$.

Delirium is associated with negative outcomes and should be prevented. The prevention and treatment of delirium is mulifactorial, and no pharmacological 
treatment has so far demonstrated significant efficacy. The knowledge of risk factors and the underlying pathophysiological mechanisms involved remains scarce, and further research is warranted to explore the mechanisms and thereby develop targeted prevention and treatment strategies.

\section{REFERENCES}

1. American Psychiatric Association. Diagnostic and statistical manual of mental disorders: DSM-IV-TR, 4th edition, 2000.

2. Cole MG, Dendukuri N, McCusker J, Han L. An empirical study of different diagnostic criteria for delirium among elderly medical inpatients. J Neuropsychiatry Clin Neurosci 2003; 15 (2): 200-7.

3. Laurila JV, Pitkala KH, Strandberg TE, Tilvis RS. Delirium among patients with and without dementia: does the diagnosis according to the DSM-IV differ from the previous classifications? Int J Geriatr Psychiatry 2004; 19 (3): 271-7.

4. Inouye SK, van Dyck CH, Alessi CA, Balkin S, Siegal AP, Horwitz RI. Clarifying confusion: the confusion assessment method. A new method for detection of delirium. Ann Intern Med 1990; 113 (12): 941-8.

5. Siddiqi N, House AO, Holmes JD. Occurrence and outcome of delirium in medical in-patients: a systematic literature review. Age Ageing 2006; 35 (4): 350-64.

6. Inouye SK. Delirium in older persons. N Engl J Med 2006; 354 (11): 1157-65.

7. Inouye SK. Predisposing and precipitating factors for delirium in hospitalized older patients. Dement Geriatr Cogn Disord 1999; 10 (5): 393-400.

8. National Clinical Guideline Centre. Delirium: diagnosis, prevention and management. www.nice.org.uk/CG103, 2010.

9. Lundstrom M, Edlund A, Lundstrom G, Gustafson Y. Reorganization of nursing and medical care to reduce the incidence of postoperative delirium and improve rehabilitation outcome in elderly patients treated for femoral neck fractures. Scand J Caring Sci 1999; 13 (3): 193-200.

10. Pitkala KH, Laurila JV, Strandberg TE, Kautiainen H, Sintonen H, Tilvis RS. Multicomponent geriatric intervention for elderly inpatients with delirium: effects on costs and health-related quality of life. $J$ Gerontol A Biol Sci Med Sci 2008; 63 (1): 56-61.

11. Lundstrom M, Olofsson B, Stenvall M, Karlsson S, Nyberg L, Englund U, et al. Postoperative delirium in old patients with femoral neck fracture: a randomized intervention study. Aging Clin Exp Res 2007; 19 (3): 178 86.

12. Marcantonio ER, Flacker JM, Wright RJ, Resnick NM. Reducing delirium after hip fracture: a randomized trial. J Am Geriatr Soc 2001; 49 (5): 516-22.

13. Vidan M, Serra JA, Moreno C, Riquelme G, Ortiz J. Efficacy of a comprehensive geriatric intervention in older patients hospitalized for hip fracture: a randomized, controlled trial. J Am Geriatr Soc $2005 ; 53$ (9): 1476-82.

14. Kalisvaart KJ, de Jonghe JF, Bogaards MJ, Vreeswijk R, Egberts TC, Burger BJ, et al. Haloperidol prophylaxis for elderly hip-surgery patients at risk for delirium: a randomized placebo-controlled study. J Am Geriatr Soc 2005; 53 (10): 1658-66.

15. Hakim SM, Othman AI, Naoum DO. Early treatment with risperidone for subsyndromal delirium after onpump cardiac surgery in the elderly: A randomized trial. Anesthesiology 2012; 116 (5): 987-97.

16. Wang W, Li HL, Wang DX, Zhu X, Li SL, Yao GQ, et al. Haloperidol prophylaxis decreases delirium incidence in elderly patients after noncardiac surgery: a randomized controlled trial. Crit Care Med 2012; 40 (3): 731-9.

17. Tagarakis GI, Voucharas C, Tsolaki F, Daskalopoulos ME, Papaliagkas V, Parisis C, et al. Ondasetron versus haloperidol for the treatment of postcardiotomy delirium: a prospective, randomized, double-blinded study. $J$ Cardiothorac Surg 2012; 7 (1): 25.

18. Duppils GS, Wikblad K. Acute confusional states in patients undergoing hip surgery. a prospective observation study. Gerontology 2000; 46 (1): 36-43.

19. Edlund A, Lundstrom M, Lundstrom G, Hedqvist B, Gustafson Y. Clinical profile of delirium in patients treated for femoral neck fractures. Dement Geriatr Cogn Disord 1999; 10 (5): 325-9.

20. Edlund A, Lundstrom M, Brannstrom B, Bucht G, Gustafson Y. Delirium before and after operation for femoral neck fracture. $J$ Am Geriatr Soc 2001; 49 (10): 1335-40.

21. Galanakis P, Bickel H, Gradinger R, Von GS, Forstl H. Acute confusional state in the elderly following hip surgery: incidence, risk factors and complications. Int J Geriatr Psychiatry 2001; 16 (4): 349-55.

22. Gustafson Y, Berggren D, Brannstrom B, Bucht G, Norberg A, Hansson LI, et al. Acute confusional states in elderly patients treated for femoral neck fracture. J Am Geriatr Soc 1988; 36 (6): 525-30.

23. Juliebo V, Bjoro K, Krogseth M, Skovlund E, Ranhoff AH, Wyller TB. Risk factors for preoperative and postoperative delirium in elderly patients with hip fracture. J Am Geriatr Soc 2009; 57 (8): 1354-61.

24. Kagansky N, Rimon E, Naor S, Dvornikov E, Cojocaru L, Levy S. Low incidence of delirium in very old patients after surgery for hip fractures. Am J Geriatr Psychiatry 2004; 12 (3): 306-14. 
25. Marcantonio ER, Flacker JM, Michaels M, Resnick NM. Delirium is independently associated with poor functional recovery after hip fracture. J Am Geriatr Soc 2000; 48 (6): 618-24.

26. Marcantonio ER, Simon SE, Bergmann MA, Jones RN, Murphy KM, Morris JN. Delirium symptoms in postacute care: prevalent, persistent, and associated with poor functional recovery. J Am Geriatr Soc 2003; 51 (1): 4-9.

27. Schuurmans MJ, Duursma SA, Shortridge-Baggett LM, Clevers GJ, Pel-Littel R. Elderly patients with a hip fracture: the risk for delirium. Appl Nurs Res 2003; 16 (2): 75-84.

28. Bruce AJ, Ritchie CW, Blizard R, Lai R, Raven P. The incidence of delirium associated with orthopedic surgery: a meta-analytic review. Int Psychogeriatr 2007; 19 (2): 197-214.

29. Dasgupta M, Dumbrell AC. Preoperative risk assessment for delirium after noncardiac surgery: a systematic review. J Am Geriatr Soc 2006; 54 (10): 1578-89.

30. Bitsch M, Foss N, Kristensen B, Kehlet H. Pathogenesis of and management strategies for postoperative delirium after hip fracture: a review. Acta Orthop Scand 2004; 75 (4): 378-89.

31. Pitkala KH, Laurila JV, Strandberg TE, Tilvis RS. Prognostic significance of delirium in frail older people. Dement Geriatr Cogn Disord 2005; 19 (2-3): 158-63.

32. Friedman SM, Mendelson DA, Kates SL, McCann RM. Geriatric co-management of proximal femur fractures: total quality management and protocol-driven care result in better outcomes for a frail patient population. J Am Geriatr Soc 2008; 56 (7): 1349-56.

33. Leibowitz D, Rivkin G, Schiffman J, Rott D, Weiss AT, Mattan Y, et al. Effect of severe aortic stenosis on the outcome in elderly patients undergoing repair of hip fracture. Gerontology 2009; 55 (3): 303-6.

34. Koster S, Oosterveld FG, Hensens AG, Wijma A, van der Palen J. Delirium after cardiac surgery and predictive validity of a risk checklist. Ann Thorac Surg 2008; 86 (6): 1883-7.

35. Andrejaitiene J, Sirvinskas E. Early post-cardiac surgery delirium risk factors. Perfusion $2012 ; 27$ (2): $105-12$.

36. Martin BJ, Buth KJ, Arora RC, Baskett RJ. Delirium: a cause for concern beyond the immediate postoperative period. Ann Thorac Surg 2012; 93 (4): 1114-20.

37. Koster S, Hensens AG, Schuurmans MJ, van der Palen J. Consequences of delirium after cardiac operations. Ann Thorac Surg 2012; 93 (3): 705-11.

38. Korevaar JC, van Munster BC, de Rooij SE. Risk factors for delirium in acutely admitted elderly patients: a prospective cohort study. BMC Geriatr 2005; 5: 6.

39. Fong TG, Tulebaev SR, Inouye SK. Delirium in elderly adults: diagnosis, prevention and treatment. Nat Rev Neurol 2009; 5 (4): 210-20.

40. Inouye SK, Zhang Y, Jones RN, Kiely DK, Yang F, Marcantonio ER. Risk factors for delirium at discharge: development and validation of a predictive model. Arch Intern Med 2007; 167 (13): 1406-13.

41. Clegg A, Young JB. Which medications to avoid in people at risk of delirium: a systematic review. Age Ageing 2011; 40 (1): 23-9.

42. Caeiro L, Ferro JM, Albuquerque R, Figueira ML. Delirium in the first days of acute stroke. J Neurol 2004; 251 (2): 171-8.

43. Sheng AZ, Shen Q, Cordato D, Zhang YY, Yin Chan DK. Delirium within three days of stroke in a cohort of elderly patients. J Am Geriatr Soc 2006; 54 (8): 1192-8.

44. Kostalova M, Bednarik J, Mitasova A, Dusek L, Michalcakova R, Kerkovsky M, et al. Towards a predictive model for post-stroke delirium. Brain Inj 2012; 26 (7-8): 962-71.

45. Ouimet S, Kavanagh BP, Gottfried SB, Skrobik Y. Incidence, risk factors and consequences of ICU delirium. Intensive Care Med 2007; 33 (1): 66-73.

46. Inouye SK, Viscoli CM, Horwitz RI, Hurst LD, Tinetti ME. A predictive model for delirium in hospitalized elderly medical patients based on admission characteristics. Ann Intern Med 1993; 119 (6): 474-81.

47. Inouye SK, Charpentier PA. Precipitating factors for delirium in hospitalized elderly persons. Predictive model and interrelationship with baseline vulnerability. JAMA 1996; 275 (11): 852-7.

48. Baranyi A, Rothenhausler HB. The impact of intra- and postoperative albumin levels as a biomarker of delirium after cardiopulmonary bypass: Results of an exploratory study. Psychiatry Res 2012 Jun 28 [Epub ahead of print].

49. Joosten E, Lemiengre J, Nelis T, Verbeke G, Milisen K. Is anaemia a risk factor for delirium in an acute geriatric population? Gerontology 2006; 52 (6): 382-5.

50. Andrew MK, Freter SH, Rockwood K. Prevalence and outcomes of delirium in community and non-acute care settings in people without dementia: a report from the Canadian Study of Health and Aging. BMC Med 2006; 4: 15.

51. Boorsma M, Joling KJ, Frijters DH, Ribbe ME, Nijpels G, van Hout HP. The prevalence, incidence and risk factors for delirium in Dutch nursing homes and residential care homes. Int J Geriatr Psychiatry $2012 ; 27$ (7): 709-15.

52. McCusker J, Cole MG, Voyer P, Monette J, Champoux N, Ciampi A, et al. Prevalence and incidence of delirium in long-term care. Int J Geriatr Psychiatry 2011; 26 (11): 1152-61.

53. Sandberg O, Gustafson Y, Brannstrom B, Bucht G. Prevalence of dementia, delirium and psychiatric symptoms in various care settings for the elderly. Scand J Soc Med 1998; 26 (1): 56-62. 
54. Cole MG, McCusker J, Voyer P, Monette J, Champoux N, Ciampi A, et al. The course of delirium in older long-term care residents. Int J Geriatr Psychiatry 2012 Apr 20 [Epub ahead of print].

55. Tune LE. How acute is delirium in nursing homes: an observational study from Wesley Woods at Emory. Am J Geriatr Psychiatry 2008; 16 (9): 786.

56. Bell RD, Zlokovic BV. Neurovascular mechanisms and blood-brain barrier disorder in Alzheimer's disease. Acta Neuropathol 2009; 118 (1): 103-13.

57. de Rooij SE, van Munster BC, Korevaar JC, Levi M. Cytokines and acute phase response in delirium. $J$ Psychosom Res 2007; 62 (5): 521-5.

58. Leonard BE. Inflammation, depression and dementia: are they connected? Neurochem Res $2007 ; 32$ (10): 1749-56.

59. Macdonald A, Adamis D, Treloar A, Martin F. C-reactive protein levels predict the incidence of delirium and recovery from it. Age Ageing 2007; 36 (2): 222-5.

60. Mancinella A, Mancinella M, Carpinteri G, Bellomo A, Fossati C, Gianturco V, et al. Is there a relationship between high C-reactive protein (CRP) levels and dementia? Arch Gerontol Geriatr 2009; 49 (Suppl 1): 185-94.

61. Ray B, Lahiri DK. Neuroinflammation in Alzheimer's disease: different molecular targets and potential therapeutic agents including curcumin. Curr Opin Pharmacol 2009; 9 (4): 434-44.

62. Jackson JC, Gordon SM, Hart RP, Hopkins RO, Ely EW. The association between delirium and cognitive decline: a review of the empirical literature. Neuropsychol Rev 2004; 14 (2): 87-98.

63. Maclullich AM, Beaglehole A, Hall RJ, Meagher DJ. Delirium and long-term cognitive impairment. Int Rev Psychiatry 2009; 21 (1): 30-42.

64. Adamis D, Treloar A, Martin FC, Macdonald AJ. A brief review of the history of delirium as a mental disorder. Hist Psychiatry 2007; 18 (72 Pt 4): 459-69.

65. Bellelli G, Frisoni GB, Turco R, Lucchi E, Magnifico F, Trabucchi M. Delirium superimposed on dementia predicts 12 -month survival in elderly patients discharged from a postacute rehabilitation facility. $J$ Gerontol A Biol Sci Med Sci 2007; 62 (11): 1306-9.

66. McCusker J, Cole M, Abrahamowicz M, Primeau F, Belzile E. Delirium predicts 12-month mortality. Arch Intern Med 2002; 162 (4): 457-63.

67. Krogseth M, Wyller TB, Engedal K, Juliebo V. Delirium is an important predictor of incident dementia among elderly hip fracture patients. Dement Geriatr Cogn Disord 2011; 31 (1): 63-70.

68. Inouye SK. Prevention of delirium in hospitalized older patients: risk factors and targeted intervention strategies. Ann Med 2000; 32 (4): 257-63.

69. Clague JE, Craddock E, Andrew G, Horan MA, Pendleton N. Predictors of outcome following hip fracture. Admission time predicts length of stay and in-hospital mortality. Injury 2002; 33 (1): 1-6.

70. Fick DM, Agostini JV, Inouye SK. Delirium superimposed on dementia: a systematic review. J Am Geriatr Soc 2002; 50 (10): 1723-32.

71. Laurila JV, Pitkala KH, Strandberg TE, Tilvis RS. Delirium superimposed on dementia predicts 12-month survival in elderly patients discharged from a postacute rehabilitation facility: a comment. J Gerontol A Biol Sci Med Sci 2008; 63 (10): 1124-5.

72. Cole MG, Ciampi A, Belzile E, Zhong L. Persistent delirium in older hospital patients: a systematic review of frequency and prognosis. Age Ageing 2009; 38 (1): 19-26.

73. Juliebo V, Krogseth M, Skovlund E, Engedal K, Ranhoff AH, Wyller TB. Delirium is not associated with mortality in elderly hip fracture patients. Dement Geriatr Cogn Disord 2010; 30 (2): 112-20.

74. Cunningham C, Campion S, Teeling J, Felton L, Perry VH. The sickness behaviour and CNS inflammatory mediator profile induced by systemic challenge of mice with synthetic double-stranded RNA (poly I: C). Brain Behav Immun 2007; 21 (4): 490-502.

75. Maclullich AM, Ferguson KJ, Miller T, de Rooij SE, Cunningham C. Unravelling the pathophysiology of delirium: a focus on the role of aberrant stress responses. J Psychosom Res 2008; 65 (3): 229-38.

76. Trzepacz PT. Update on the neuropathogenesis of delirium. Dement Geriatr Cogn Disord 1999; 10 (5): $330-4$.

77. Trzepacz PT. Is there a final common neural pathway in delirium? Focus on acetylcholine and dopamine. Semin Clin Neuropsychiatry 2000; 5 (2): 132-48.

78. Perry VH, Cunningham C, Holmes C. Systemic infections and inflammation affect chronic neurodegeneration. Nat Rev Immunol 2007; 7 (2): 161-7.

79. Backman L, Nyberg L, Lindenberger U, Li SC, Farde L. The correlative triad among aging, dopamine, and cognition: current status and future prospects. Neurosci Biobehav Rev 2006; 30 (6): 791-807.

80. German DC, Manaye KF, White CL, III, Woodward DJ, McIntire DD, Smith WK, et al. Disease-specific patterns of locus coeruleus cell loss. Ann Neurol 1992; 32 (5): 667-76.

81. Roman GC, Kalaria RN. Vascular determinants of cholinergic deficits in Alzheimer disease and vascular dementia. Neurobiol Aging 2006; 27 (12): 1769-85.

82. Pfister D, Siegemund M, Dell-Kuster S, Smielewski P, Ruegg S, Strebel SP, et al. Cerebral perfusion in sepsis-associated delirium. Crit Care 2008; 12 (3): R63. 